\title{
56. Using a Printer
}

Output on the screen is suitable for many uses - but often a hard copy (i.e. printed on paper) will be required.

A document to be printed is treated as a file and each line is seen as a record. So if you want to use the printer - the Environment Division has to have an entry specifying a file name and the device (often just 'PRINTER') - e.g.

SELECT STUDENT-REPORT-FILE ASSIGN TO PRINTER.

(This will vary between computer systems - so consult the COBOL manual).

As with any other file, the File Section of the Data Division must have a suitable area specified to hold one record (line) until it is ready to be written. This line will be the same length as the line-length being used on your printer (e.g. 80 or 132 characters) - e.g.

FD STUDENT-REPORT-FILE

01 STUDENT-REPORT-LINE PIC X(80).

As each line on the report will have a different layout - it is normal to have a number of different working lines in the Working-Storage Section - but these will each be the same length as the report-line already specified - e.g.

01 STUDENT-NAME-LINE.

05 FILLER PIC X(11) VALUE 'REPORT FOR '.

05 STUDENT-NAME PIC X(30).

05 FILLER PIC X(39) VALUE SPACES.

01 STUDENT-GRADE-LINE.

05 FILLER PIC X(6) VALUE 'GRADE'

05 STUDENT-GRADE PIC X(15).

05 FILLER PIC X(59) VALUE SPACES.

Within the Procedure Division, as with any other file, the printer file has to be opened and each line is written to the file when it is ready (generally after being moved from the relevant working-storage line).

e.g.

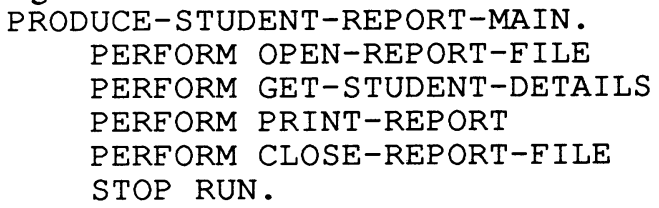

